\title{
Submitted: Gallbladder diseases in pregnancy: Sonographic findings Accepted: in an indigenous African population
} 22.11.2019

Published: 31.12.2019

Keywords gallstones, sludge. pregnancy, ultrasonography

\author{
Bukunmi Michael Idowu', Stephen Olaoluwa Onigbinde², \\ Isaiah Uzezi Ebie ${ }^{1}$, Michael Temidayo Adeyemi ${ }^{1}$
}

${ }^{1}$ Department of Radiology, Union Diagnostics and Clinical Services Plc, Yaba, Lagos, Nigeria ${ }^{2}$ Department of Radiology, Obafemi Awolowo University Teaching Hospitals Complex, Ile - Ife, Osun state, Nigeria

Correspondence: Dr. Bukunmi M. IDOWU, Union Diagnostics and Clinical Services Plc, No 37 Tejuosho Street, Yaba,Lagos,Nigeria; e-mail: ibmcontacts@gmail.com

DOI: $10.15557 / J o U .2019 .0040$

\begin{abstract}
Aim of the study: This study aimed to evaluate the prevalence of gallbladder disease in gravid Nigerian women and to elucidate any association with gravidity and ABO blood group. Materials and Methods: This was a descriptive cross-sectional study of six hundred and fifty-six (656) pregnant women recruited from March 2015 to March 2016. Hemoglobin genotype and blood group were recorded and a sonographic examination was performed using Siemens ultrasound scanner. Statistical analysis was done using STATA software for Windows. Results: Age had a significant association with the occurrence of gallbladder diseases (Likelihood ratio $=7.116, P=0.03)$. Two $(0.3 \%)$ pregnant women had biliary sludge, $11(1.7 \%)$ had gallstones while $643(98 \%)$ had normal gallbladders. Also, only one (9.1\%) primigravida woman with gallstone was found in this study while 10 (90.9\%) of the women with gallstones were multigravida. All the pregnant women who had gallstone(s) had blood group O. Of the two women with biliary sludge; one had blood group A while the other had blood group O. Conclusions: The incidence of gallbladder disease increased with age in this study. There was a higher prevalence of gallstones than sludge in pregnancy. Also, the incidence of gallstones increased with the number of pregnancies among the women with gallstones. Attention should be paid to the gallbladder during abdominal sonography in pregnancy.
\end{abstract}

\section{Introduction}

During pregnancy, gallbladder disease is often due to gallstones and biliary sludge ${ }^{(1)}$. Although gallbladder disease also occurs in men, a higher prevalence has been reported in women ${ }^{(2,3)}$. Hossain et al. ${ }^{(4)}$ reported that gall bladder diseases are four times more common in women than men. Likewise, Eze et al. reported a male-to-female ratio of 2.8:1 in the prevalence of these diseases ${ }^{(2)}$. This gender predilection constitutes a risk during pregnancy, and it has been found that gall bladder disease is the second most common indication for non-obstetric surgical intervention in pregnancy ${ }^{(1)}$. Gallbladder disease in pregnancy is reportedly higher among multigravid women ${ }^{(5)}$.
The prevalence of gallbladder disease also varies with geographical location. For example, in the United States, $10 \%-15 \%$ of the adult population has gallstones. In other populations, such as those of Latin-American countries, the prevalence of gallstones is higher, up to $50 \%$ in adult women $^{(1)}$. The prevalence of gallstones in Africa is low, even though this varies from one part of the continent to another ${ }^{(2,6-8)}$. With respect to race, $70 \%$ of Native American women older than 30 years of age develop cholelithiasis. Mexican American women have an intermediate prevalence of about $14 \%$, with Caucasians and Black women at $4 \%$ and $5 \%$, respectively. Chilean women are also reported to be at high risk for developing gallstones ${ }^{(9)}$. 


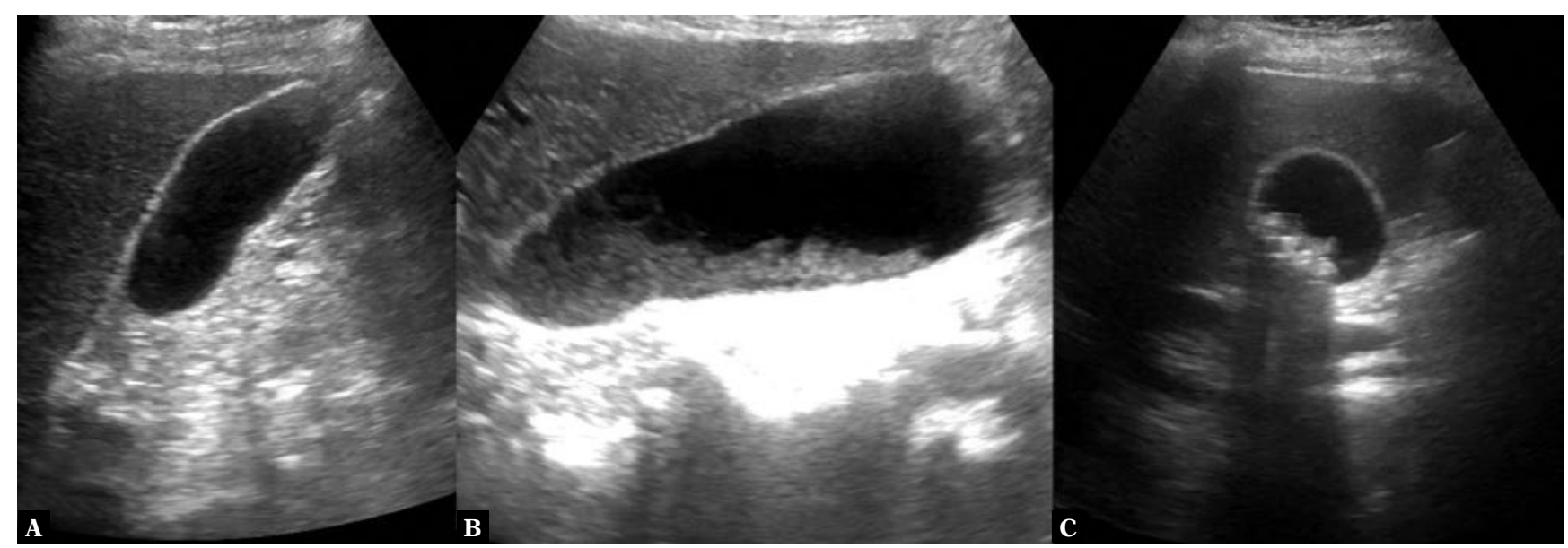

Fig. 1. Sonograms of the gallbladder showing a normal gallbladder with anechoic lumen (A), layering sludge (B), and gallstones casting posterior acoustic shadows (C)

A number of risk factors for gallbladder disease have been identified; the most important ones being obesity (and its consequence, the metabolic syndrome), diet and hormones ${ }^{(1)}$. The risk factors for gallbladder disease during pregnancy include history of gallbladder disease, high body mass index, and prenatal physical activity ${ }^{(1)}$. Gallbladder disease in pregnancy may be due to an increased level of estrogen during pregnancy that causes an indirect increase in cholesterol saturation of bile ${ }^{(5)}$. It could also be as a result of the inhibition of gallbladder contractility which may be caused by a higher level of progesterone ${ }^{(10)}$.

The purpose of this study was to evaluate the prevalence, pattern, and characteristics of gallbladder disease in gravid Nigerian women and to elucidate any association of gallbladder disease in pregnancy with gravidity and ABO blood group.

\section{Materials and methods}

This was a descriptive cross-sectional study of six hundred and fifty six gravid women at Union Diagnostics and Clinical Services Plc, Yaba, Lagos state, Nigeria from March 2015 to March 2016. The institutional board approved the study. All the participants were recruited consecutively after informed consent had been obtained. Only asymptomatic and clinically stable women were enrolled. Biodata was obtained by oral interviews. Hemoglobin genotype and blood group were retrieved from the subjects' antenatal clinic cards.

Siemens ultrasound scanner model GM-6800A2E00 (Siemens AG, Erlangen, Germany) with a convex transducer (frequency range $=3.5-6.0 \mathrm{MHz}$ ) was used for the sonographic examinations. Hepatobiliary sonography was performed with the patient lying supine, augmented with left posterior oblique positioning as necessary. The third and fourth authors who have 10 and 8 years' experience with abdominopelvic and obstetrics sonography, respectively, performed the sonographic evaluations.
The normal gallbladder (Fig. $1 \mathrm{~A}$ ) is seen on ultrasound as a pear-shaped, hollow organ with anechoic lumen ${ }^{(11)}$. Biliary sludge (Fig. 1 B) is low-level echoes without acoustic shadowing that layer in the dependent portion of the gallbladder or may fill its entire lumen ${ }^{(12)}$. Ultrasonographic features of gallstones include a highly reflective echo from the anterior surface of the gallstone (Fig. 1 C), mobility of the gallstone with change in subjects' position, and marked posterior acoustic shadowing ${ }^{(13)}$. Gallbladder wall thickening $>3 \mathrm{~mm}$ with sonographic Murphy's sign with/without pericholecystic fluid was regarded as acute calculous cholecystitis ${ }^{(11)}$. Subjects with previous cholecystectomy, ascites, diabetes mellitus, metabolic syndrome, and pre-existing hepatobiliary diseases were excluded.

Gravidity was defined as the sum of all pregnancies (including all live births and pregnancies that terminated at $<6$ months or did not result in a live birth $)^{(14)}$. The subdivisions of gravidity were: primigravida (first pregnancy), multigravida (2-5 pregnancies), and grandmultigravida (>5 pregnancies) $)^{(15)}$.

The study data were analyzed using STATA (StataCorp LLC Texas, USA) software version 16 for Windows. Normality was determined using the Kolmogorov-Smirnov's test. Categorical variables like gallbladder status and blood group were presented using frequency tables. The mean values of age, gestational age, and gravidity were compared Mann Whitney U. Gallbladder status was compared to age group, gravidity, trimester, genotype, and blood group using the likelihood-ratio Chi-squared test. Statistical significance was set at $P \leq 0.05$.

\section{Results}

Table 1 shows the demographic data of subjects. The mean age of the subjects was $30.95 \pm 4.56$ years (range, 18-44 years) (Tab. 2). Table 3 shows the comparison of means of pregnant women with and without cholelithiasis; women with cholelithiasis had a higher mean age, gestational age and gravidity. 
Tab. 1. Descriptive statistics of subjects

\begin{tabular}{|c|c|c|c|}
\hline Parameter & & Frequency & Percent \\
\hline \multirow{4}{*}{$\begin{array}{l}\text { Gallbladder } \\
\text { status }\end{array}$} & Normal & 643 & 98.0 \\
\hline & Stone(s) & 11 & 1.7 \\
\hline & Sludge & 2 & 0.3 \\
\hline & Total & 656 & 100.0 \\
\hline \multirow{4}{*}{$\begin{array}{l}\text { Gravidity } \\
\text { group }\end{array}$} & Primigravida & 232 & 35.4 \\
\hline & Multigravida & 281 & 42.8 \\
\hline & Grandmultigravida & 143 & 21.8 \\
\hline & Total & 656 & 100.0 \\
\hline \multirow{4}{*}{$\begin{array}{l}\text { Gallbladder } \\
\text { status }\end{array}$} & Normal & 643 & 98.0 \\
\hline & Stone(s) & 11 & 1.7 \\
\hline & Sludge & 2 & 0.3 \\
\hline & Total & 656 & 100.0 \\
\hline \multirow{5}{*}{ Blood group } & A & 97 & 14.8 \\
\hline & B & 70 & 10.7 \\
\hline & $\mathrm{O}$ & 467 & 71.2 \\
\hline & $A B$ & 22 & 3.3 \\
\hline & Total & 656 & 100.0 \\
\hline \multirow{4}{*}{ Trimester } & $1 \mathrm{st}$ & 76 & 11.6 \\
\hline & 2nd & 256 & 39.0 \\
\hline & $3 r d$ & 324 & 49.4 \\
\hline & Total & 656 & 100.0 \\
\hline \multirow{5}{*}{ Genotype } & $A A$ & 533 & 81.2 \\
\hline & AS & 114 & 17.4 \\
\hline & $A C$ & 8 & 1.2 \\
\hline & SS & 1 & 0.2 \\
\hline & Total & 656 & 100.0 \\
\hline \multirow{5}{*}{ Age group } & $11-20$ & 5 & 0.8 \\
\hline & $21-30$ & 312 & 47.6 \\
\hline & $31-40$ & 325 & 49.5 \\
\hline & $41-50$ & 14 & 2.1 \\
\hline & Total & 656 & 100.0 \\
\hline
\end{tabular}

Tab. 2. Mean and standard deviation of patient demographics

\begin{tabular}{|l|c|c|c|}
\hline & N & Mean & $\begin{array}{c}\text { Standard } \\
\text { deviation }\end{array}$ \\
\hline Age & 656 & 30.95 & 4.562 \\
\hline Gestational age & 656 & 25.18 & 8.786 \\
\hline Gravidity & 656 & 2.21 & 1.240 \\
\hline
\end{tabular}

Tab. 3. Comparison of pregnant women with and without cholelithiasis

\begin{tabular}{|l|c|c|c|c|c|c|}
\hline & \multicolumn{2}{|c|}{$\begin{array}{c}\text { Cholelithiasis } \\
(\boldsymbol{n}=\mathbf{1 1})\end{array}$} & \multicolumn{2}{|c|}{$\begin{array}{c}\text { No } \\
\text { Cholelithiasis } \\
(\boldsymbol{n = 6 4 5 )}\end{array}$} & \multirow{2}{*}{ U } & \multirow{2}{*}{$\boldsymbol{P}$} \\
\cline { 1 - 5 } & Mean & SD & Mean & SD & & \\
\hline Age (years) & 32.73 & 3.85 & 30.92 & 4.57 & 2563.5 & 0.11 \\
\hline GA (weeks) & 26.45 & 9.81 & 25.16 & 8.78 & 3168.5 & 0.54 \\
\hline Gravidity & 2.73 & 1.35 & 2.20 & 1.24 & 2.653 & 0.13 \\
\hline
\end{tabular}

Of all the parameters studied, age group had a significant association with the occurrence of gallbladder disease (Likelihood ratio $=7.116, P=0.029)$. Two $(18.2 \%)$ of subjects with gallstone(s) were $<31$ years old while $9(81.8 \%)$ were $\geq 31$ years old. All $(100 \%)$ of the pregnant women studied who had biliary sludge were $\geq 31$ years old (Tab. 4).

Out of the 656 pregnant women enrolled, $643(96 \%)$ had normal gallbladder, $11(1.7 \%)$ had gallstones (cholelithiasis) and $2(0.3 \%)$ had sludge. There were no cases of cholecystitis. Two hundred and thirty-two (35.4\%) were primigravida while $424(64.6 \%)$ had two or more pregnancies. There was one $(9.1 \%)$ primigravid woman with gallstone, while $10(90.9 \%)$ of the women with gallstones had two or more pregnancies (Tab. 4). The number of pregnant women with biliary sludge was one each in the gravid groups (Tab. 4).

Most of the subjects [467 (71.2\%)] had blood group O, followed by blood group B in $70(10.7 \%)$ subjects. Ninetyseven (14.8\%) subjects had blood group A while 22 (3.4\%) had blood group AB (Tab. 1). All the pregnant women with gallstones had blood group $\mathrm{O}$. Of the two women with biliary sludge, one had blood group A while the other had blood group $\mathrm{O}$ (Tab. 4).

In total, $76(11.6 \%)$ of the subjects were in the first trimester, $256(39 \%)$ in the second trimester, while $317(48.3 \%)$ were in the third trimester. Seven $(63.6 \%)$ of the 11 women with gallstones were in the third trimester while two $(18.2 \%)$ were in the second and third trimesters, respectively. Also, the two subjects with biliary sludge were in the third trimester (Tab. 4).

The pregnant women with hemoglobin genotype AA were $533(81.2 \%)$ while $123(18.8 \%)$ had hemoglobinopathies (both trait and clinical disease). Seven (63.6\%) of the 11 subjects with gallstones had hemoglobin AA while 4 (36.4\%) had hemoglobinopathies. The two women (100\%) who had biliary sludge had hemoglobin AA (Tab. 4).

Table 5 is a succinct comparison of this study to previous studies.

\section{Discussion}

A spectrum of gallbladder diseases in pregnancy has been reported ${ }^{(16)}$. Even though many imaging modalities 
Tab. 4. Cross-tabulation of subjects' demographics and gallbladder status

\begin{tabular}{|c|c|c|c|c|c|c|}
\hline & \multicolumn{6}{|c|}{ Gallbladder status, N (row \%, column \%) } \\
\hline & Normal & Stone(s) & Sludge & Total & $x^{2}$ & Pvalue \\
\hline \multicolumn{7}{|l|}{ Age group } \\
\hline$<31$ years & $315(49.0)$ & $2(18.2)$ & $0(0.0)$ & $317(48.3)$ & 7.116 & 0.029 \\
\hline$\geq 31$ years & $328(51.0)$ & $9(81.8)$ & $2(100.0)$ & $339(51.7)$ & & \\
\hline \multicolumn{7}{|l|}{ Gravidity } \\
\hline Primigravida & $230(35.8)$ & $1(9.1)$ & $1(50.0)$ & $232(35.4)$ & & \\
\hline Multigravida & $275(42.8)$ & $6(54.5)$ & $0(0)$ & $281(42.8)$ & 6.694 & 0.153 \\
\hline Grandmultigravida & $138(21.5)$ & $4(36.4)$ & $1(50.0)$ & $143(21.8)$ & & \\
\hline \multicolumn{7}{|l|}{ Trimester } \\
\hline 1 & $74(11.5)$ & $2(18.2)$ & $0(0.0)$ & $76(11.6)$ & & \\
\hline 2 & $254(39.5)$ & $2(18.2)$ & $0(0.0)$ & $256(39.0)$ & 5.179 & 0.269 \\
\hline 3 & $315(49.0)$ & $7(63.6)$ & $2(100.0)$ & 324 (49.4) & & \\
\hline \multicolumn{7}{|l|}{ Genotype } \\
\hline AA & $524(81.5)$ & $7(63.6)$ & $2(100.0)$ & $533(81.2)$ & & \\
\hline AS & $111(17.3)$ & $3(27.3)$ & $0(0.0)$ & $114(17.4)$ & 10.263 & 0.114 \\
\hline AC & $8(1.2)$ & $0(0.0)$ & $0(0.0)$ & $8(1.2)$ & & \\
\hline SS & $0(0.0)$ & $1(9.1)$ & $0(0.0)$ & $1(0.2)$ & & \\
\hline \multicolumn{7}{|l|}{ Blood group } \\
\hline A & $96(14.9)$ & $0(0.0)$ & $1(50.0)$ & $97(14.8)$ & & \\
\hline B & $70(10.9)$ & $0(0.0)$ & $0(0.0)$ & 70 (10.7) & 9.268 & 0.159 \\
\hline 0 & $455(70.8)$ & $11(100.0)$ & $1(50.0)$ & $467(71.2)$ & & \\
\hline$A B$ & $22(3.4)$ & $0(0.0)$ & $0(0.0)$ & $22(3.4)$ & & \\
\hline
\end{tabular}

(CT, MRI, radionuclide imaging, magnetic resonance cholangiopancreatography - MRCP, endoscopic retrograde cholangiopancreatography - ERCP, etc.) could be used to evaluate the gallbladder and/or biliary tree, ultrasonography is the preferred imaging method in gravid women because it is fast, cheap, sensitive, and does not use ionizing radiation ${ }^{(9)}$. Cholelithiasis and biliary sludge were the gallbladder pathologies seen in this study.

Age had a significant association with the occurrence of gallbladder disease (Likelihood ratio $=7.116 ; P=$ 0.03). This is similar to findings in a study by Ferguson et al. where a significant correlation was found between patients' age and an increased prevalence of gallstones: the incidence of calculi was $2.9 \%$ in patients younger than 22 years of age and $5.8 \%$ in patients $\geq 22$ years old $(P=0.031)^{(17)}$. Similarly, Gangwar et al. ${ }^{(5)}$ found a statistically significant correlation between gallbladder diseases and advanced age, while Saha et al. reported that adults (both male and female) of age below 40 years were more affected ${ }^{(18)}$. Tica et al. also reported that the prevalence of biliary disorders is higher in older multiparous pregnant women who are in the third trimes$\operatorname{ter}^{(19)}$. Two $(18.2 \%)$ of the subjects with gallstones in the study were $<31$ years old while $9(81.8 \%)$ were $\geq 31$ years old. All (100\%) of the pregnant women with biliary sludge were $\geq 31$ years old.
There was one $(9.1 \%)$ primigravida woman with gallstone in this study while 10 (90.9\%) of the women with gallstones had two or more pregnancies. This is in line with a number of studies which show that the incidence of gallstone increases with the number of pregnancies ${ }^{(4,20)}$. However, the review by Watemberg et al. stated that while some studies show a relationship between gravidity and gallstone occurrence, others have failed to show this relationship ${ }^{(10)}$.

In contrast to eleven women with stones, two women had biliary sludge. A number of clinical events and conditions have been associated with the formation of biliary sludge $\mathrm{e}^{(21)}$. Biliary sludge is a mixture of bile precipitate and bile, which is believed to be transient and a precursor to the formation of bile stones ${ }^{(21)}$.

In this study, all the pregnant women who had gallstone(s) [11 (100\%)] had blood group O. Of the two women with biliary sludge, one had blood group A while the other had blood group $\mathrm{O}$. According to our results, blood group $\mathrm{O}$ was the commonest blood group seen followed by group A. This is at variance with other studies in our locality where blood group B was the second commonest. The population was also found to be in Hardy-Weinberg equilibrium $^{(22)}$.

In total, $76(11.6 \%)$ of the pregnant women in this study were in the 1 st trimester, $256(39 \%)$ were in the 2 nd 
Tab. 5. Gallbladder sonographic findings in pregnant women around the world

\begin{tabular}{|c|c|c|c|c|c|c|c|c|}
\hline Study & Country & Year & Design & Sample Size & Age group (years) & Stone (\%) & Sludge (\%) & Other findings \\
\hline Stauffer ${ }^{(25)}$ & USA & 1982 & $\mathrm{P}$ & 338 & $24-40$ & $3.5 \%$ & NS & Nil \\
\hline Bartoli $^{(26)}$ & Italy & 1984 & $\mathrm{P}$ & 36 & $20-34$ & $5.6 \%$ & $36 \%$ & Nil \\
\hline Williamson $^{(27)}$ & USA & 1984 & $P$ & 142 & $19-40$ & $11.3 \%$ & NS & NS \\
\hline $\operatorname{Mintz}^{(28)}$ & USA & 1985 & $P$ & 103 & $N P$ & $3.9 \%$ & $2 \%$ & Nil \\
\hline Christenson $^{(29)}$ & USA & 1986 & $P$ & 175 & NP & $6.3 \%$ & NS & NS \\
\hline Maringhini(30) & Italy & 1987 & $P$ & 298 & $26.8 \pm 5.7$ & $5.2 \%$ & $26.2 \%$ & Nil \\
\hline Sali ${ }^{(31)}$ & Australia & 1989 & $\mathrm{P}$ & 121 & $16-42$ & $4.1 \%$ & $\mathrm{Nil}$ & $\mathrm{Nil}$ \\
\hline Basso $^{(32)}$ & Ireland & 1992 & $P$ & 512 & $15-43$ & $4.5 \%$ & Nil & Nil \\
\hline Valdivieso $^{(33)}$ & Chile & 1993 & $P$ & 980 & $16-30$ & $12.2 \%$ & NS & NS \\
\hline Maringhini ${ }^{(34)}$ & Italy & 1993 & $P$ & 272 & $27.0 \pm 5.0$ & $2 \%$ & $31 \%$ & Nil \\
\hline Giangrande $\mathrm{e}^{(23)}$ & Italy & 1993 & $\mathrm{P}$ & 56 & $\mathrm{~N}$ & $2.9 \%$ & $10.7 \%$ & NS \\
\hline Tsimoyiannis (20) & Greece & 1994 & $P$ & 669 & $25.0 \pm 3.0$ & $2 \%$ & NS & NS \\
\hline Deutchman $^{(35)}$ & USA & 1994 & $P$ & 228 & $13-40$ & $5.3 \%$ & NS & PLP \\
\hline Hansen $^{(36)}$ & USA & 1994 & $P$ & 585 & $15-42$ & $5.3 \%$ & NS & $\mathrm{Nil}$ \\
\hline Ferguson $^{(17)}$ & USA & 1994 & $\mathrm{P}$ & 572 & $\mathrm{NP}$ & $4.2 \%$ & NS & NS \\
\hline De Alba ${ }^{(37)}$ & Mexico & 1997 & $P$ & 292 & $\mathrm{~N}$ & $14.04 \%$ & $0.68 \%$ & PLP, CHL \\
\hline Bodegraven $^{(38)}$ & NTHLD & 1998 & $P$ & 111 & $29.1 \pm 4.1$ & $5.4 \%$ & $42.3 \%$ & $\mathrm{Nil}$ \\
\hline Akute $^{(39)}$ & Nigeria & 1999 & $P$ & 3832 & $15-54$ & $2.1 \%$ & NS & $\mathrm{Nil}$ \\
\hline Rambal ${ }^{(40)}$ & India & 2001 & $\mathrm{P}$ & 200 & $16-40$ & $6 \%$ & $18 \%$ & $\mathrm{Nil}$ \\
\hline Hossain ${ }^{(4)}$ & Banglad & 2003 & $\mathrm{P}$ & 1336 & $20-45$ & $8.08 \%$ & $\mathrm{U}$ & $\mathrm{U}$ \\
\hline Lindseth $^{(41)}$ & USA & 2004 & $P$ & 128 & $18-40$ & $12.5 \%$ & NS & NS \\
\hline $\mathrm{Ko}^{(42)}$ & USA & 2005 & $P$ & 3254 & $N P$ & $1.8 \%$ & $4.5 \%$ & NS \\
\hline Bolukbas $^{(43)}$ & Turkey & 2006 & $\mathrm{P}$ & 97 & 19-35 & $6.3 \%$ & $10.9 \%$ & NS \\
\hline Tica $^{(19)}$ & Romania & 2010 & $\mathrm{P}$ & 130 & Md: 25.11 & $9.23 \%$ & $33.85 \%$ & NS \\
\hline Moghaddam (44) & Iran & 2013 & $P$ & 380 & $26.3 \pm 5.0$ & $0.7 \%$ & $3.7 \%$ & Nil \\
\hline Ibitoye $\mathrm{e}^{(24)}$ & Nigeria & 2014 & $P$ & 1283 & $14-43$ & $2.9 \%$ & $2 \%$ & PLP \\
\hline Ilhan ${ }^{(45)}$ & Turkey & 2016 & $\mathrm{R}$ & 96567 & $28.0 \pm 5.0$ & $0.06 \%+$ & NS & $\mathrm{AC}, \mathrm{GSP}, \mathrm{CHG}, \mathrm{CHDL}$ \\
\hline Kolbeinsson ${ }^{(46)}$ & Iceland & 2016 & $\mathrm{R}$ & 77000 & Mn: 29 & $0.09 \%$ & NS & $\mathrm{AC}, \mathrm{GSP}, \mathrm{CHG}, \mathrm{CHDL}$ \\
\hline Ramirez $^{(47)}$ & Mexico & 2016 & $\mathrm{P}$ & 348 & $15-35$ & $16 \%$ & NS & PLP \\
\hline Idowu & Nigeria & 2019 & $P$ & 656 & $18-44$ & $1.7 \%$ & $0.3 \%$ & $\mathrm{Nil}$ \\
\hline
\end{tabular}

trimester and $317(48.3 \%)$ were in the 3rd trimester. Most [7 (63.6\%)] of the pregnant women with gallstones were in the 3 rd trimester. There were two (18.2\%) in the first and second trimesters, respectively. This correlates with literature, as most gallstones have been reported during the second and third trimester ${ }^{(23)}$. Also, the two pregnant women who had biliary sludge were both in the third trimester. This finding is similar to those of a study by Mendez-Sanchez et al. ${ }^{(1)}$ who documented that new sludge or stones were found in $30 \%$ and $2 \%$ of the women, respectively, at the end of their pregnancies. Contrarily, Giangrande et al. observed that gallstones were found at ultrasound examination in 5 out of 56 women in the first trimester (one woman with gallstones, 4 with sludge) and 9 out of 49 women examined in the third trimester $(2 \text { women with gallstones, } 7 \text { with sludge })^{(20)}$. This present study shows a higher incidence of gallstones compared to sludge in pregnant women.
Five hundred and thirty three $(81.2 \%)$ of the pregnant women studied had hemoglobin genotype AA, 114 (17.4\%) were AS, $12(1.4 \%)$ were AC, and $1(0.2 \%)$ was SS. Gallstones were identified on ultrasound in 7 of $533(1.3 \%)$ AA patients, 3 of $114(27.3 \%)$ AS patients, and in the only SS patient (100\%). The trend of an increasing prevalence with the presence of haemoglobin S, is similar to findings obtained by Ibitoye et al. ${ }^{(24)}$. Ibitoye et al. studied 633 women and identified gallstones on ultrasound in 17 of 633 $(2.7 \%)$ AA patients, 6 of $168(3.6 \%)$ AS patients, and 2 of 6 (33.3\%) SS patients ${ }^{(24)}$.

\section{Conclusions}

In conclusion, age had a significant association with the occurrence of gallbladder disease in this study. There was a higher prevalence of gallstones than sludge. The incidence 
of gallstones increased with the number of pregnancies. A similar statement cannot be made for those with sludge as only two were detected. The majority of the gallstone and biliary sludge cases were in women in the third trimester.

Being cross-sectional, this study was unable to ascertain the exact period of onset of biliary stones and sludge. However, its findings suggest the need for including abdominopelvic scan in routine obstetric examination. This is important in women at higher risk of biliary stone

\section{References}

1. Mendez-Sanchez N, Chavez-Tapia NC, Uribe M: Pregnancy and gallbladder disease. Ann Hepatol 2006; 5: 227-230.

2. Eze CU, Ezugwu EE, Ohagwu CC: Prevalence of cholelithiasis among Igbo adult subjects in Nnewi, Southeast Nigeria: A Community-Based Sonographic Study. J Diagn Med Sonogr 2017; 33: 83-90.

3. Njeze GE: Gallstones. Niger J Surg 2013; 19: 49-55.

4. Hossain GA, Islam SM, Mahmood S, Chakrabarty RK, Akhter N: Gall stone in pregnancy. Mymensingh Med J 2003; 12: 112-116.

5. Gangwar R, Dayal M, Dwivedi M, Ghosh UK: Gallbladder disease in pregnancy. J Obstet Gynaecol India 2011; 61: 57-61.

6. Akute OO, Obajimi MO: Cholelithiasis in Ibadan: an update. West Afr J Med 2002; 21: 128-131.

7. Rahman GA: Cholelithiasis and cholecystitis: changing prevalence in an African community. J Natl Med Assoc 2005; 97: 1534-1538.

8. Gyedu A, Adae-Aboagye K, Badu-Peprah A: Prevalence of cholelithiasis among persons undergoing abdominal ultrasound at the Komfo Anokye Teaching Hospital, Kumasi, Ghana. Afr Health Sci 2015; 15: 246-252.

9. Casey BM, Cox SM: Cholecystitis in pregnancy. Infect Dis Obstet Gynecol 1996; 4: 303-309.

10. Watemberg S, Avrahami R, Landau O, Kott I, Deutsch AA: Gallstone disease in pregnancy: mere coincidence or physiologic response? Dig Surg 1995; 12: 148-151.

11. Barbosa ABR, Souza LRMF de, Pereira RS, D'Ippolito G: Gallbladder wall thickening at ultrasonography: how to interpret it? Radiol Bras 2011; 44: 381-387.

12. Shaffer EA: Gallbladder sludge: What is its clinical significance? Curr Gastroenterol Rep 2001; 3: 166-173.

13. Bortoff GA, Chen MY, Ott DJ, Wolfman NT, Routh WD: Gallbladder stones: imaging and intervention. Radiographics 2000; 20: 751-766.

14. Wernli KJ, Wang Y, Zheng Y, Potter JD, Newcomb PA: The relationship between gravidity and parity and colorectal cancer risk. J Womens Health (Larchmt) 2009; 18: 995-1001.

15. Ishola A, Asaleye CM, Ayoola OO, Loto OM, Idowu BM: Reference ranges of fetal cerebral lateral ventricle parameters by ultrasonography. Rev Bras Ginecol Obstet 2016; 38: 428-435.

16. Heller MT, Tublin ME, Hosseinzadeh K, Fargiano A: Imaging of hepatobiliary disorders complicating pregnancy. AJR Am J Roentgenol 2011; 197: W528-W536.

17. Ferguson TK, Anderson JC, Fisher CR, Harned RK: Cholelithiasis in pregnant women: prevalence and risk factors. J Diagn Med Sonogr 1994; 10: 104-107.

18. Saha M, Nahar K, Hosen MA, Khan MH, Kumar Saha S, Shil BC et al. Prevalence and risk factors of asymptomatic gallstone disease in northeast part of Bangladesh. Euroasian J Hepatogastroenterol 2015; 5: 1-3.

19. Tica I, Tica VI, Teren O: Pregnancy, parity and maternal age - predictive factors for occurrence of billiary pathology (gallstones and sludge)? Gineco Ro 2010; 6: 218-222.

20. Tsimoyiannis EC, Antoniou NC, Tsaboulas C, Papanikolaou N: Cholelithiasis during pregnancy and lactation. Prospective study. Eur J Surg 1994; 160: 627-631.

21. Ko CW, Sekijima J, Lee S: Biliary sludge. Ann Int Med 1999; 130: 301-311. and sludge such as those who are in their thirties and are multigravida.

\section{Conflict of interest}

Authors do not report any financial or personal connections with other persons or organizations, which might negatively affect the contents of this publication and/or claim authorship rights to this publication.
22. Faduyile FA, Ojewale AO, Osuolale FI: Frequency of ABO and Rhesus blood groups among blood donors in Lagos, Nigeria. Int J Med Biomed Res 2016; 5: 114-121.

23. Giangrande M, Russo F, Coviello A, Trentadue R, Di Masi M, Guerra V et al.: Calculi and sludge in the gallbladder during pregnancy. Minerva Ginecol 1993; 45: 159-163.

24. Ibitoye BO, Adisa AO, Makinde ON, Ijarotimi AO: Prevalence and complications of gallstone disease among pregnant women in a Nigerian hospital. Int J Gynecol Obstet 2014; 125: 41-43.

25. Stauffer RA, Adams A, Wygal J, Lavery JP: Gallbladder disease in pregnancy. Am J Obstet Gynecol 1982; 144: 661-664.

26. Bartoli E, Calonaci N, Nenci R: Ultrasonography of the gallbladder in pregnancy. Gastrointest Radiol 1984; 9: 35-38.

27. Williamson SL, Williamson MR: Cholecystosonography in pregnancy. J Ultrasound Med 1984; 3: 329-331.

28. Mintz MC, Grumbach K, Arger PH, Coleman BG: Sonographic evaluation of bile duct size during pregnancy. Am J Roentgenol 1985; 145: 575-578.

29. Christenson R, Hopper K, Komppa GH, Ghaed N: Cholecystosonography in pregnancy. J Ultrasound Med 1986; 5: 592.

30. Maringhini A, Marcenò MP, Lanzarone F, Caltagirone M, Fusco G, Di Cuonzo G et al.: Sludge and stones in gallbladder after pregnancy. Prevalence and risk factors. J Hepatol 1987; 5: 218-223.

31. Sali A, Oats JN, Acton CM, Elzarka A, Vitetta L: Effect on pregnancy on gallstone formation. Aust N Z J Obstet Gynaecol 1989; 29: 386-389.

32. Basso L, McCollum PT, Darling MR, Tocchi A, Tanner WA: A study of cholelithiasis during pregnancy and its relationship with age, parity, menarche, breast-feeding, dysmenorrhea, oral contraception and a maternal history of cholelithiasis. Surg Gynecol Obstet 1992; 175: 41-46.

33. Valdivieso V, Covarrubias C, Siegel F, Cruz F: Pregnancy and cholelithiasis: pathogenesis and natural course of gallstones diagnosed in early puerperium. Hepatology 1993; 17: 1-4.

34. Maringhini A, Ciambra M, Baccelliere P, Raimondo M, Orlando A, Tinè F et al.: Biliary sludge and gallstones in pregnancy: incidence, risk factors, and natural history. Ann Intern Med 1993; 119: 116-120.

35. Deutchman ME, Connor P, Hahn RG, Rodney WM: Maternal gallbladder assessment during obstetric ultrasound: results, significance, and technique. J Fam Pract 1994; 39: 33-37.

36. Hansen GC, Duerinckx AJ, Fymat A, Wong L, Ngo C: Cholelithiasis in the gravid Hispanic population. J Clin Ultrasound 1994; 22: 187-191.

37. de Alba-Quintanilla F, Posadas-Robledo FJ: Ultrasonic evaluation of the gallbladder during pregnancy. Ginecol Obstet Mex 1997; 65: 39-42.

38. Van Bodegraven AA, Böhmer CJ, Manoliu RA, Paalman E, Van der Klis AH, Roex AJ et al.: Gallbladder contents and fasting gallbladder volumes during and after pregnancy. Scand J Gastroenterol 1998; 33: 993-997.

39. Akute OO, Marinho AO, Kalejaiye AO, Sogo K: Prevalence of gall stones in a group of antenatal women in Ibadan, Nigeria. Afr J Med Med Sci 1999; 28: 159-161.

40. Rambal S, Manhas K, Sharma S, Gupta S: Ultrasound evaluation of gallbladder disease in pregnancy. JK Science 2001; 3: 78-83.

41. Lindseth G, Bird-Baker MY: Risk factors for cholelithiasis in pregnancy. Res Nurs Health 2004; 27: 382-391. 
42. Ko CW, Beresford SA, Schulte SJ, Matsumoto AM, Lee SP: Incidence, natural history, and risk factors for biliary sludge and stones during pregnancy. Hepatology 2005; 41: 359-365.

43. Bolukbas FF, Bolukbas C, Horoz M, Ince AT, Uzunkoy A, Ozturk A et al.: Risk factors associated with gallstone and biliary sludge formation during pregnancy. J Gastroenterol Hepatol 2006; 21: 1150-1153.

44. Galyani Moghaddam T, Fakheri H, Abdi R, Khosh Bavar Rostami F, Bari Z: The incidence and outcome of pregnancy-related biliary sludge/ stones and potential risk factors. Arch Iran Med 2013; 16: 12-16.
45. İlhan M, İlhan G, Gök AFK, Günay K, Ertekin C: The course and outcomes of complicated gallstone disease in pregnancy: Experience of a tertiary center. Turk J Obstet Gynecol 2016; 13: 178-182.

46. Kolbeinsson HM, Hardardottir H, Birgisson G, Moller PH: Gallstone disease during pregnancy at Landspitali University Hospital 19902010. Laeknabladid 2016; 102: 538-542.

47. Ibarra Ramirez CT, Ortiz LG, Alberto Ramirez LC: Asymptomatic colelithiasis in pregnant patients in the primary care level. Gynecol Obstet (Sunnyvale) 2016; 6:392. 